\title{
Espaços de significação e regime de informação: aproximação entre conceitos
}

\author{
Meaning spaces and information regime: approximation between concepts \\ Emy Pôrto Bezerra \\ Doutor em Ciência da Informação \\ Universidade Federal de Campina Grande \\ emyporto@gmail.com
}

\author{
Maria Elizabeth Baltar Carneiro de Albuquerque \\ Doutora em Letras \\ Universidade Federal da Paraíba \\ ebaltar2007@gmail.com \\ Isa Maria Freire \\ Doutora em Ciência da Informação \\ Universidade Federal da Paraíba \\ isafreire@globo.com
}

\begin{abstract}
Resumo
Sugere uma aproximação conceitual entre dois temas ainda em construção na Ciência da Informação: o conceito de Espaços de Significação, proposto por Francelin (2012), e o de Regime de Informação, proposto por González de Gómez (2003). Analisa o conceito de Espaço de Significação no contexto de um laboratório de pesquisa científica, especificamente a ação de informação formativa no contexto do Regime de Informação do Laboratório de Aplicações em Vídeo Digital (LAVID) da Universidade Federal da Paraíba, referência em tecnologia digital para TV e cinema. Argumenta que a ação de registro (memória) da pesquisa científica na forma de artigos, dissertações, livros e periódicos, constituem-se numa ação de informação formativa desenvolvida pelos atores sociais deste espaço. Conclui que, através da forma de linguagem ou forma de vida entre seus atores, o LAVID pode ser considerado um espaço de significação com seu respectivo Regime de Informação.
\end{abstract}

Palavras-chave

Espaços de significação. Regime de informação. Ação de informação formativa.

\begin{abstract}
It suggests a conceptual approach between two issues still under construction in Information Science: the concept of Meaning spaces proposed by Francelin (2012), and the Information System, proposed by González de Gómez (2003). Analyzes the concept of Meaning Area in the context of a scientific research laboratory, specifically the action of training information in the context of the Information System Applications Laboratory of Digital Video (LAVID) of the Federal University of Paraiba, in digital technology reference for $T V$ and film. It argues that the record of action (memory) of scientific research in the form of articles, dissertations, books and periodicals, constitute a formative information program developed by social actors from space. It concludes that, by way of language or way of life among its actors, the LAVID can be considered a significance space with their respective Information System.
\end{abstract}

Keywords

Spaces of meaning. Information system. Formative action information.

DOI: $10.28998 /$ cirev.2020v7n2a

Submetido em: 01/08/2019

Aceito em: 28/06/2020

Este artigo está licenciado sob uma Licença Creative Commons 4.0

Publicado em: 31/08/2020

Ci. Inf. Rev., Maceió, v. 7, n. 2, p. 7-18, maio/ago. 2020 


\section{INTRODUÇÃO}

Este artigo propõe um debate de aproximação entre os conceitos de Espaço de Significação, conforme Francelin (2012), e Regime de Informação, conforme González de Gómez (2003), no contexto da abordagem de uma ação de informação (a formativa), no campo de pesquisa da Ciência da Informação.

Enfatizamos a importância da relação entre ações de informação, representação do conhecimento e formação da cultura, entendendo a cultura como estrutura de significações e processo de produção de sentidos. Sendo assim, esta rede ou trama do saber vem testemunhando um crescente e frutífero debate na elaboração de dois recentes conceitos na Ciência da Informação sem associá-los diretamente, são eles: o conceito de Regime de Informação e o de Espaços de Significação.

Baseado no referencial teórico analisado sobre os dois temas, acreditamos que ambos sejam por natureza constituídos a partir de suas respectivas "ações de informação"1. Deste modo, e a fim de tentar provar tal hipótese, tomamos como campo de pesquisa um ambiente de produção científica e tecnológica: o Laboratório de Aplicação em Vídeo Digital (LAVID) do Departamento de Informática da Universidade Federal da Paraíba (DI/UFPB).

A partir da descrição e interpretação desta ação de informação, tentaremos situar a produção científica do LAVID como resultante de um Espaço de Significação no âmbito do Regime de Informação da sociedade em rede. Deste modo, esperamos aprofundar a discussão no tema, sem a pretensão de fazer um mapeamento exaustivo, mas com a preocupação em analisar a construção de espaços públicos de pesquisa nos quais se desenvolvem Regimes de Informação e Espaços de Significação.

\section{SOBRE ESPAÇOS DE SIGNIFICAÇÃO}

Antes de compreender o que sejam Espaços de Significação, convém tentar entender o que seja significação. Segundo Barreto (2005, p. 114), "O ato de significação é criado a partir dos encontros que o indivíduo tem com o mundo, mediado por atividades simbólicas no entendimento do homem como um ser atuante na cultura e através dela [...]". O autor compartilha a visão de autores como Piaget, Vygotsky e Bruner, que enfatizam o papel da linguagem na construção de significados. Para Bruner (1997), a questão da construção do "eu", por meio do "nós", só vai ocorrer pela troca das experiências que acontecem no cotidiano, no dia-a-dia do mundo empírico. Mais além, Santaella (1997) compreende que qualquer ato de informar atrela-se ao significado das coisas, dos fatos, dos acontecimentos, o que fundamenta a cultura. Podemos depreender dessas colocações, que há um diálogo entre informação e conhecimento, um trânsito que passa pelo simples dado bruto (representação de fatos, textos, gráficos, sinais, etc.), transformado em informação quando processado para produção de conhecimento.

Nesse sentido, presenciamos, atualmente, intensas e rápidas mudanças na esfera da cultura, oriundas principalmente dos novos processos comunicacionais na sociedade, que além de acelerar o acesso às informações permitem novas formas de trocas de experiências e relacionamentos no mundo da política, dos negócios, do entretenimento e da própria relação entre pessoas. Para Luckesi e Passos (2002), é da apropriação que o sujeito faz do exte-

1 Conjunto de determinações onde estão definidos os elementos que compõem o fluxo estrutural da produção, organização, comunicação e transferência de informações desenvolvidas em um dado regime de informação. 
rior que nascem os conceitos. Este seria o exercício direto de produção de sentido pelo sujeito, pois não podemos conceber uma apropriação sem sentido. Esse sentido é elaborado pelo sujeito como informação e por essa proximidade o conceito de "Espaços de Significação" vem sendo recentemente desenvolvido por pesquisadores no campo da Ciência da Informação. Este artigo representa uma incursão reflexiva nessa área de interesse, e para produzi-lo nos baseamos no conceito de Francelin (2012, p. 80) onde "Os espaços de significação são ambientes de criação artística, cultural e científica. Locais onde a representação do conhecimento é dinâmica e constante, pois dependem da ação de seus sujeitos.". Ainda conforme o autor,

[...] os espaços de informação são locais onde comunidades lingüísticas definidas exercem sua autonomia de produção e uso de conceitos e, por extensão, da informação e do conhecimento. Desenvolvem e preservam desta forma, uma memória conceitual (e informacional) com características próprias, ou seja, locais [...] (MARTINS; SOARES; FRANCELIN, 2012, p. 79).

Englobam-se a esses locais, principalmente ambientes periféricos de produção, uso e organização de conhecimentos (conceitos e memória informacional), ou seja, periferias linguísticas ou de significação. Para Francelin (2012), estas se referem à compreensão do que pode ser "válido" ou "não-válido" na esfera do conhecimento, especialmente no campo do chamado senso comum. Ainda conforme o autor, hipoteticamente, e apenas nesse sentido, características dos espaços de significação podem ser identificadas em qualquer ambiente (científico, religioso, filosófico, etc.). No caso dos laboratórios científicos existe a tradição dos paradigmas, não havendo, no momento, outra forma de tratá-los a não ser pelo viés kuhniano. Thomas Kuhn (1997), numa leitura da inovação de seus conceitos, identifica que todo paradigma precisa de muitos fatores para se estabelecer em um campo de pesquisa, mas de nada adianta se os pesquisadores não "acreditarem" nele. Ou seja, o princípio da crença é válido para a ciência em sua condição mais tensa e importante: aprovação coletiva.

Mesmo não sendo um ambiente de produção de conhecimento periférico (senso comum), visto que a linguagem científica tem o respaldo da sua comunidade e da sociedade, o LAVID pode ser analisado (mesmo que hipoteticamente) como um espaço de significação, demonstrando que os Espaços de Significação não se restringem a locais pré-determinados, podendo ser analisados em qualquer ambiente, inclusive nas memórias das pessoas que constroem seus modelos de saberes carregados de significado.

\section{LAVID COMO ESPAÇO DE SIGNIFICAÇÃO}

Criado em 2003, o LAVID é atualmente uma referência nacional e internacional em desenvolvimento de tecnologia para TV Digital, contando com a colaboração de mais de 40 jovens pesquisadores, supervisionados por cerca de 20 docentes-pesquisadores que estão interconectados com pesquisadores do Brasil e do mundo, trazendo as atuais tendências tecnológicas mundiais nas áreas de vídeo e TV Digital.

As pesquisas desenvolvidas são realizadas em parceria com outras universidades, institutos de pesquisa e empresas da iniciativa privada. Por ser um laboratório ativo na área de desenvolvimento, recebe financiamento de instituições de fomento ao desenvolvimento científico e tecnológico, como Rede Nacional de Ensino e Pesquisa (RNP), Financiadora de Estudos e Projetos (FINEP) e Conselho Nacional de Desenvolvimento Científico e Tecnológico (CNPq). Além do trabalho científico, os pesquisadores do LAVID estão envolvidos em ativida- 
des acadêmicas, como pode ser observado na forte participação do grupo em eventos nacionais e internacionais, bem como nas publicações em coautoria e patentes que divulgam a produção técnico-científica do laboratório.

Analisando o LAVID sob o ponto de vista de um Espaço de Significação podemos entendê-lo não como um espaço físico, mas pela constituição, unidade e preservação de uma cultura através da sua identidade linguística, neste caso, um espaço de linguagem, onde podem coexistir sentidos, significados e significações. Deste modo, os pesquisadores do LAVID devem ser reconhecidos não pelo local de onde "falam", mas pela linguagem que utilizam. É através da linguagem que são reconhecidos pelos seus pares, ou seja, reconhecidos pelo uso que fazem do sistema conceitual de uma área de conhecimento. Para Francelin (2012, p. 80, grifos do autor),

\footnotetext{
A comunicação entre os membros de um determinado grupo social requer regras que sejam compartilhadas. Portanto, [...] A informação que circula em tal grupo possui relação direta com sua cultura, constituindo uma "cultura informacional". Toda cultura desenvolve características próprias a partir de seu contexto referencial, tornando-se seletiva com as informações, principalmente com as "ações de informação".
}

Destarte, o uso que os pesquisadores do LAVID fazem dos dispositivos constituídos pelas regras de comunicação, determina, diante de outros grupos de pesquisadores, quais espaços desejam conquistar no complexo linguístico da ciência, adquirindo assim status e, consequentemente, influência no discurso científico daquela especialidade. No caso do LAVID, as aplicações tecnológicas para vídeo e TV digital.

\section{O CONCEITO DE REGIME DE INFORMAÇÃO}

Na sociedade contemporânea, o campo teórico da gestão da informação abre cada vez mais a discussão sobre o valor da informação e a necessária democratização do acesso às suas fontes digitais. Neste contexto, autores como Frohmann (1984), González de Gómez (2012), Freire (2013), Braman (2004) e Ekbia e Evans (2009) vêm levantando o debate sobre as ações de informação que compõem o Regime de Informação das diversas formações (instituições públicas ou privadas) sociais, na sociedade em rede. Entendemos, portanto, que o Regime de Informação se constitui pela relação de seus elementos (atores, dispositivos, tecnologias) através de ações de informação relacionadas à produção e às políticas de informação de espaços sociais (públicos e privados).

Quando falamos em regime, logo vem à tona a ideia de regras, normas e modelos. Ele oferece definições operacionais, estabelece uma hierarquia de valores e define regras de negociação e procedimentos. Um regime inclui normas éticas e comportamentais, práticas culturais, hábitos, estruturas de conhecimento, formas organizacionais, processos decisórios individuais e do setor privado, as tecnologias, as leis formais e todas as regulamentações de governos oficialmente reconhecidos. Nesse sentido, foram se constituindo diversos tipos de regime (político, jurídico, social, etc.).

Nos últimos anos, o conceito de Regime de Informação vem sendo desenvolvido por diversos pesquisadores da Ciência da Informação, sempre com características gerais similares, porém, sem analisar ainda, as particularidades e necessidades do contexto (ambiente/espaço) onde se originam ou se instalam. Segundo Unger e Freire (2008) os Regimes de Informação são a substância que dão o caráter principal a uma formação social que passou por diferentes e longos estágios até chegar ao atual. Para Frohmann (1995, p. 17, tradução 
nossa) "[...] pode ser definido como qualquer sistema estável ou rede nos quais os fluxos informacionais transitam por determinados canais [de específicos produtores, via estruturas organizacionais específicas] para consumidores ou usuários específicos.". Conforme González de Gómez (2002, p. 34), o Regime de Informação é

\begin{abstract}
Um modo de produção informacional dominante numa formação social, conforme o qual serão definidos sujeitos, instituições, regras e autoridades informacionais, os meios e os recursos preferenciais de informação, os padrões de excelência e os arranjos organizacionais de seu processamento seletivo, seus dispositivos de preservação e distribuição.
\end{abstract}

Como um plexo de relações e agências, um regime de informação está exposto a certas possibilidades e condições culturais, políticas e econômicas, que nele se expressam e nele se constituem (GONZÁLEZ DE GÓMEZ, 2003). Segundo Magnani e Pinheiro (2011, p. 596, grifo das autoras),

\footnotetext{
O "regime de informação" ou o "regime global de política de informação" são conceitos que vem sendo trabalhados na Ciência da Informação como uma forma de se obter uma paisagem do campo de ação da política de informação relacionando atores, tecnologias, representações, normas, e padrões regulatórios que configuram políticas implícitas ou explícitas de informação.
}

O construto de "regime de informação" proposto por González de Gómez (1999a,b, 2002, 2003, 2004) designa o modo de produção informacional numa formação social, no qual ficaria estabelecido quem são os sujeitos, as organizações, as regras e as autoridades normativas no campo da informação. Trata-se do conjunto de determinações onde estão definidos os elementos que compõem o fluxo estrutural da produção, organização, comunicação e transferência de informações em um dado espaço social. São elementos de um regime de informação:

a) Dispositivos de informação: considerados um mecanismo operacional, ou um conjunto de meios composto de regras de formação e de transformação desde o seu início, ou ainda, como a autora exemplifica, "um conjunto de produtos e serviços de informação e das ações de transferência de informação" (GONZÁLEZ DE GÓMEZ, 1999b, p. 63);

b) Atores sociais: "reconhecidos por suas formas de vidas e [que] constroem suas identidades através de ações formativas existindo algum grau de institucionalização e estruturação das ações de informação". (GONZÁLEZ DE GÓMEZ, 2003, p. 35). Os atores estão intrinsecamente relacionados às ações de informação, que propõem e desenvolvem no âmbito de um regime de informação.

c) Artefatos de informação: que constituem os modos tecnológicos e materiais de armazenagem, processamento e de transmissão de dados, mensagem, informação. (GONZÁLEZ DE GÓMEZ, 2002, 2003).

Usando uma representação gráfica, Delaia (2008) destaca as relações entre os elementos do regime de informação, conforme Figura 1. 
Figura 1 - Relações entre elementos de um regime de informação

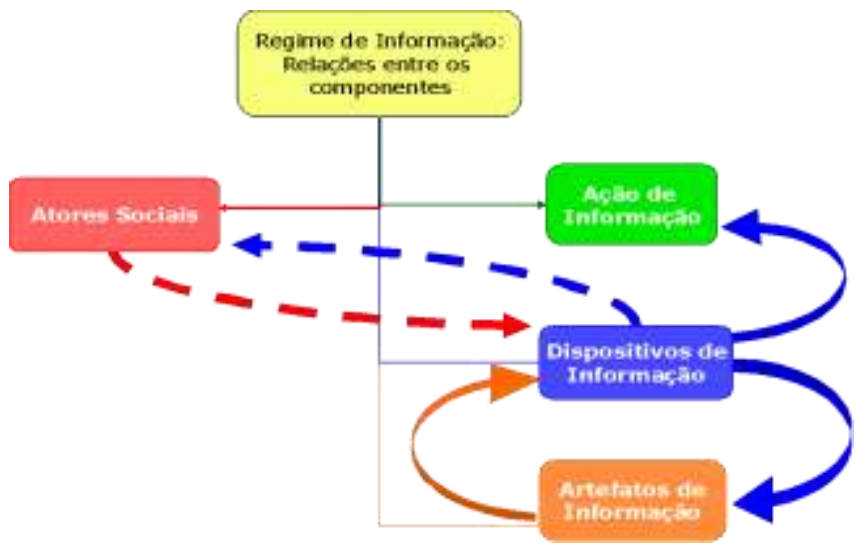

Fonte: Delaia (2008).

Entendemos que as ações de informação no LAVID são desenvolvidas por sujeitos identificados como docentes-pesquisadores e pesquisadores em formação, no escopo dos dispositivos representados pelos diversos projetos de pesquisa em desenvolvimento, os quais utilizam as tecnologias digitais para se apropriar e também produzir artefatos de informação. Nesse contexto a Ciência da Informação é:

[...] aquela que estuda fenômenos, processos, construções, sistemas, redes e artefatos de informação, enquanto "informação" for definida por ações de informação, as quais remetem aos atores que as agenciam aos contextos e situações em que acontecem e aos regimes de informação em que se inscrevem. (GONZÁLEZ DE GÓMEZ, 2003, p. 32, grifo da autora).

Assim, a Ciência da Informação justifica, fundamenta e dá respaldo a abordagem do LAVID na perspectiva do Regime de Informação. Ademais, o conceito de Regime de Informação pode ser visto como uma importante ferramenta para análise das relações de uma pluralidade de atores, práticas e recursos, à luz da transversalidade específica de ações, meios e efeitos de informação.

Acreditamos, portanto, que o Regime de Informação se constitui pela relação entre seus elementos (atores, dispositivos e tecnologias) através das ações de informação relacionadas à produção e às políticas de informação de espaços sociais (públicos e privados), tornando-os passíveis de uma aproximação e análise ao que ora chamamos ou identificamos como Espaço de Significação.

\subsection{Ações de informação}

Tendo em vista que as ações de informação são essencialmente um fenômeno social, pois são partes integrantes da vida diária das comunidades e organizações, torna-se cada vez mais evidente que a integração entre as tecnologias "colaborativas" transporte consigo uma profunda revisão nos Regimes de Informação de uma determinada instituição (bem como na linguagem desse Espaço de Significação). Neste sentido, González de Gómez (2003) reconhece três modalidades de manifestação de uma ação de informação, conforme o contexto de sua constituição em um dado Regime de Informação: 
a) Mediação: quando a ação de informação fica atrelada aos fins e orientação de uma outra ação;

b) Formativa: aquela que é orientada à informação não como meio, mas como sua finalização;

c) Relacional: quando uma ação de informação tem como finalidade intervir numa outra ação de informação, de modo que, ainda quando de autonomia relativa, dela obtém a direção e fins.

A autora apresenta uma sistematização com a teleologia das ações de informação, relacionando as ações aos sujeitos, atividades e finalidades, conforme Quadro 1.

Quadro 1 - Teleologia das ações de informação

\begin{tabular}{|l|l|l|l|}
\hline \multicolumn{1}{|c|}{ Ações de Informação } & \multicolumn{1}{|c|}{ Atores } & \multicolumn{1}{c|}{ Atividades } & \multicolumn{1}{c|}{ [Finalidade] } \\
\hline Mediação & $\begin{array}{l}\text { Sujeitos Sociais Funcio- } \\
\text { nais }\left(\text { práxis }^{2}\right)\end{array}$ & $\begin{array}{l}\text { Atividades Sociais Múlti- } \\
\text { plas }\end{array}$ & $\begin{array}{l}\text { Transformar o mundo } \\
\text { social ou natural }\end{array}$ \\
\hline Formativa ou Finalista & $\begin{array}{l}\text { Sujeitos Sociais Experi- } \\
\left.\text { mentadores (poiesis }{ }^{3}\right)\end{array}$ & $\begin{array}{l}\text { Atividades Heurísticas e } \\
\text { de Inovação }\end{array}$ & $\begin{array}{l}\text { Transformar o conheci- } \\
\text { mento para transformar } \\
\text { o mundo }\end{array}$ \\
\hline $\begin{array}{l}\text { Relacional } \\
\text { Inter-Meta-Pós- } \\
\text { mediática }\end{array}$ & $\begin{array}{l}\text { Sujeitos Sociais Articula- } \\
\text { dores e Reflexivos (le- } \\
\left.\text { gein }^{4}\right)\end{array}$ & $\begin{array}{l}\text { Atividades Sociais de } \\
\text { Monitoramento, Contro- } \\
\text { le e Coordenação }\end{array}$ & $\begin{array}{l}\text { Transformar a informa- } \\
\text { ção e a comunicação } \\
\text { que orientam o agir } \\
\text { coletivo }\end{array}$ \\
\hline
\end{tabular}

Fonte: González de Gómez (2003, p.37).

Assim, posto que o discurso científico se consolide por meio de ações ou atos públicos, a linguagem enquadra-se numa dessas ações. Um ato público em que sujeitos, falando num contexto de significação, apresentam uns aos outros suas pretensões e as materializam por algum tipo de registro da memória.

Los pensamientos, experiencias, ilusiones, emociones y hallazgos de acceso público, esto es, registrados em libros, periódicos, fotografias, audio visuales o multimídia ocupan um lugar particular em nuestra memoria exterior, em laexomemoria. Esa ubicación se manifesta a través de criterios y códigos elaborados em complejos procesos de mediación em los que intervienen elementos cognitivos que escapan al control de los propios mediadores. (GARCÍA GUTIÉRREZ, 2004, p. 9).

Não é à toa que a escrita e outras formas de registro do pensamento provocaram tamanhas mudanças na memória coletiva da humanidade. Sendo assim, a informação registrada numa determinada "plataforma" necessita primeiramente ser acessada para que pos-

2 Práxis - No campo científico, entende-se como uma prática profissional em que os atores sociais atuam a partir de uma teoria que é a base para sua ação no mundo.

3 Poiesis - "[...] quando a ação de informação no contexto formativo é gerada por sujeitos sociais heurísticos ou 'experimentadores', transformando os modos culturais de agir e de fazer, nas artes, na política, na ciência, na indústria e no trabalho, iniciando um novo domínio informacional." (GONZÁLEZ DE GÓMEZ, 2003, p. 36. grifo nosso).

4 Legein - "[...] quando uma ação de informação intervém em [uma] outra [...], duplicando o espaço de realização [desta, de modo a ampliar as] formas de descrição, da facilitação, do controle ou do monitoramento, [...] realizadas por sujeitos articuladores ou relacionantes." (GONZÁLEZ DE GÓMEZ, 2003, p. 36). 
sa fazer algum sentido. São as nossas ações de informação que determinam os sentidos que uma informação poderá produzir no sujeito que a está acessando.

Para o presente artigo, entendemos a ação de informação formativa (ação polimórfica ou de forma de vida) como àquela que permeia, alicerça e "alimenta" os dois termos acima descritos (Regime de Informação e Espaços de Significação).

\title{
4.2 Ação formativa
}

Percebendo as funções primordiais dos atores e suas respectivas ações, inferimos que os Regimes de Informação podem ser concebidos como fenômenos, sistemas, redes, regras e artefatos de informação circunscritos a um determinado espaço de significação, ou seja, desde que entendamos "informação" como ações de informação desenvolvidas por atores, contextos e situações as quais se inscrevem. Nesse sentido, González de Gómez (2003) propõe a reconstrução do que sejam "ações de informação" (ação social ou forma de vida) entendendo que uma "forma de vida" se constitui pelas interações duradouras de um grupo que partilha de atividades, situações e experiências comuns.

Para o presente artigo, nos fundamentamos na proposta de trabalho de Collins e Kush (1999), que consideram que as "ações formativas" "são aquelas constitutivas de uma forma de vida a qual singularizam e diferenciam em relação a outros modos de ação e formas de vida" (GONZÁLEZ DE GÓMEZ, 2003, p. 36). Portanto, tais ações têm caráter formativo e definem o que uma sociedade é e no que se diferencia de outras sociedades.

\footnotetext{
Uma ação formativa, por exemplo, na academia, é apresentar uma comunicação num congresso. [...] O que "fixa" um significado, um discurso, ou pode pré configurar um "artefato de informação" em alguma de suas dimensões, não seria logo e em primeiro lugar a base material da inscrição, e sim as condições institucionais e as relações socioculturais entre os sujeitos - incluídas as relações de poder que articulam os artefatos e as infraestruturas de informação em regimes de informação. (GONZÁLEZ DE GÓMEZ, 2003, p. 35, grifos da autora).
}

A autora também concorda com Collins e Kush $(1999$, p. 19) no tocante a que estratos ou dimensões das ações de informação admitem outras leituras, conforme se trate de ações polimórficas ou ações mimeomórficas, esclarecendo:

\begin{abstract}
Ações polimórficas são aquelas que só podem ser compreendidas por quem participa de uma cultura ou forma de vida. Nesse caso, a mesma ação, na mesma situação, pode ser executada conforme um número indefinido de comportamentos e, ao mesmo tempo, uma mesma instância de comportamento pode dar lugar a muitas diferentes ações. Dado que são ações determinadas por regras, o modo "correto" de praticá-las só é possível para quem participa da forma de vida que é o contexto da ação. (GONZÁLEZ DE GÓMEZ, 2003, p. 34).
\end{abstract}

Aqui percebemos que tanto o conceito de Espaço de Significação quanto o de Regime de Informação se constituem a partir das ações de informação provenientes da interação entre seus atores sociais. No caso específico da ação de informação formativa do LAVID, entendemos que este compreendido como Espaço de Significação é responsável pela manutenção da memória científica e, principalmente, pela transmissão de ideologias, culturas e crenças, que são indissociáveis de todo e qualquer conhecimento produzido. Assim os atores sociais "podem ser reconhecidos por suas formas de vida e constroem suas identidades através de ações formativas existindo algum grau de institucionalização e estruturação das 
ações de informação" (GONZÁLEZ DE GÓMEZ, 2003, p. 35). Já os artefatos de informação constituem os modos tecnológicos e materiais de armazenagem, processamento e de transmissão de dados, mensagem, informação (GONZÁLEZ DE GÓMEZ, 2002, 2003).

No âmbito do LAVID, a ação de informação formativa promove o compartilhamento de recursos de informação e a comunicação científica dos resultados (eventos, publicações, patentes, etc.), desenvolvendo entre seus membros uma sinergia para o trabalho, gerando comprometimento para sua execução e para o benefício do coletivo, além de reunir Ciência da Informação e Computação em nível da integração da pesquisa na práxis acadêmica.

\section{CONSIDERAÇÕES FINAIS}

Conforme descrito no início, o presente artigo propôs-se a trazer ou estimular uma breve reflexão sobre dois conceitos ainda em construção na Ciência da Informação. Nossa pretensão, a priori, não foi demonstrar a existência de uma relação entre os seus conceitos, apenas evidenciar pontos comuns que possam justificar ou contribuir para reforçar uma possível ou provável relação entre eles. Adotamos para tanto, a concepção de ação de informação formativa a fim de promover um elo que permeia tanto o tear conceitual de Regime de Informação quanto o de Espaços de Significação. Acreditamos que tal ação, expressa, principalmente, através da linguagem utilizada pelos seus atores, evidenciada no que se refere ao registro da informação (memória, documentos, site, artigos, dissertações, etc.), é uma propensa atividade responsável por essa aproximação. Sendo assim, não buscamos aqui relacionar seus conceitos, mas apenas aproximá-los no intuito de propor a abertura de um discurso a partir de um ponto comum de constituição (ações de informação, mas especificamente, ações formativas). Ações estas que, conforme González de Gómez (2003), são oriundas de sujeitos sociais experimentadores que executam atividades heurísticas e de inovação com a finalidade de transformar o conhecimento para transformar o mundo.

Este ponto de vista enquadra-se perfeitamente no contexto do LAVID, um espaço social onde seus atores produzem conhecimentos que transformam a nossa realidade e nossa forma de perceber o mundo. Ao mesmo tempo, tais ações podem ser compreendidas como um exercício direto de produção de sentido pelo sujeito. E é justamente esse sentido elaborado como informação pelo sujeito que contribui para aproximação dessas ações ao conceito de Espaços de Significação.

Observamos, no entanto, que os Espaços de Significação, ao contrário do que percebemos nos Regimes de Informação, nem sempre necessitam ser enquadrados ou "materializados" na forma física (ambiente), onde as pessoas vivem, andam e trabalham; ao contrário, são esses lugares que geralmente "moram" nas pessoas, sendo, portanto, seus modelos de saberes, espaços em suas memórias "habitados" por uma série de significados. São suas "formas de vida", constituintes da sua cultura, atualmente potencializadas graças à alteração no acesso e circulação da informação na sociedade. Geralmente frutos da nossa interação com o mundo, pois é ao saírem de si e enxergar os outros, que os seres humanos instauram o espaço sociocultural, e, neste, estabelecem suas significações. A partir daí, acreditamos que cada nova configuração de um Regime de Informação resulta de e condiciona diferentes modos de configuração de uma ordem sociocultural e política, e consequentemente, de novos Espaços de Significação.

Entendemos que a clara representação dos Espaços de Significação e Regimes de Informação - como se originam e se estabilizam, como determinam as relações sociais e como são exercidas suas formas de vida/poder - se apresenta como um legítimo e premente cam- 
po de pesquisa em gestão e políticas de informação, ainda pouco abordados no campo da Ciência da Informação.

Assim, esperamos ter contribuído para uma aproximação conceitual entre os dois termos (Regime de Informação e Espaços de Significação). Acreditamos que esta aproximação só se faz possível através da busca constante por novos entendimentos da natureza de suas dinâmicas e processos. Só assim, poderemos tentar compreender os fios que tecem o tear conceitual dos Regimes de Informação e Espaços de Significação na sociedade em rede. Convidamos os pesquisadores e demais interessados no assunto a participar dessa jornada em busca de regimes e formas de vida em espaços de significação no âmbito da pesquisa científica que porventura possam contribuir para a efetiva transparência e transferência de informação na sociedade.

\section{REFERÊNCIAS}

BARRETO, A. M. Informação e conhecimento na era digital. Transinformação, Campinas, v. 17, n. 2, p. 111-122, maio/ago. 2005. Disponível em:

https://www.scielo.br/pdf/tinf/v17n2/02.pdf. Acesso em: 20 maio 2020.

BRAMAN, S. The emergent global information policy regime. In: BRAMAN, S. (Ed.) The emergent global information policy regime. Hampshire, Palgrave, 2004.

BRUNER, J. Atos de significação. Porto Alegre: Artes Médicas, 1997.

COLLINS, H. M.; KUSH, M. The shapeofactions: what humansand machines can do. Cambridge, Mass: MIT Press, 1999. p. 11-21.

DELAIA, C. R. Subsídios para uma política de gestão da informação na EMBRAPA Solos. 2008. 137f. Dissertação (Mestrado em Ciênciad a Informação). Instituto Brasileiro de Informação em Ciência e Tecnologia-Universidade Federal Fluminense, 2008.

EKBIA, H.; EVANS, T. Regimes of information: land use, management, and policy. The Information Society, v. 25, n. 5, p. 328-343, 2009.

FRANCELIN, M. M. Espaços de significação. PontodeAcesso, Salvador, v.6, n.1, p.75-91, 2012. Disponível em: https://portalseer.ufba.br/index.php/revistaici/article/view/4981/4344.

Acesso em: 20 maio 2020.

FREIRE. I. M. Sobre o Regime de Informação no Laboratório de Tecnologias Intelectuais - LTi. InCID: Revista de Ciência da Informação e Documentação, Ribeirão Preto, v. 4, n. 1, p. 70-86, jan./jun. 2013. Disponível em: http://www.revistas.usp.br/incid/article/view/59102/62100. Acesso em: 20 maio 2020.

FROHMANN, B. Talking information policy beyond Information Science: applying the actor network theory. In: OLSON, H. A.; WARD, D. B. (Eds.). Proceedings of the 23rd Annual conference of the Canadian Association for Information Science, Edmonton, Alberta, Jun. 1995. 
GARCÍA GUTIÉRREZ, A. La memoria subrogada: mediación, cultura y concienciaenlared digital. Granada: Universidad de Granada, 2002.

GARCÍA GUTIÉRREZ, A. Outra memoria es posible: estrategias descolonizadoras delarchivo mundial. Sevilla: Universidad de Sevilla, 2004.

GONZÁLEZ DE GÓMEZ, M. N. Caráter seletivo das ações de informação. Informare, v. 5, n. 2, p. 7-31, 1999a. Disponível em:

https://ridi.ibict.br/bitstream/123456789/126/1/GomezInformare1999.pdf. Acesso em: 20 maio 2020.

GONZÁLEZ DE GÓMEZ, M. N. Da política de informação ao papel da informação na política contemporânea. Revista Internacional de Estudos Políticos, v. 1, n. 1, p. 57-93, 1999b.

GONZÁLEZ DE GÓMEZ, M. N. Escopo e abrangência da Ciência da Informação e a PósGraduação na área: anotações para uma reflexão. Transinformação, Campinas, v. 15, n.1, p. 31-43, jan./abr. 2003. Disponível em: https://www.scielo.br/pdf/tinf/v15n1/02.pdf. Acesso em: 20 maio 2020.

GONZÁLEZ DE GÓMEZ, M. N. Novos cenários políticos para a informação. Ciência da Informação, Brasília, v. 31, n. 1, p. 27-40, jan./abr. 2002. Disponível em: http://revista.ibict.br/ciinf/article/view/975/1013. Acesso em: 20 maio 2020.

GONZÁLEZ DE GÓMEZ, M. N. Novas fronteiras tecnológicas das ações de informação: questões e abordagens. Ciência da Informação, Brasília, v. 33, n. 1, 2004. Disponível em: http://revista.ibict.br/ciinf/article/view/1068/1160. Acesso em: 20 maio 2020.

GONZÁLEZ DE GÓMEZ, M. N. Regime de informação: construção de um conceito. Informação \& Sociedade: Estudos, João Pessoa, v. 22, n. 3, p. 43-60, set./dez. 2012. Disponível em: https://periodicos.ufpb.br/ojs2/index.php/ies/article/view/14376/8576. Acesso em: 20 maio 2020.

KUHN, T. S. A estrutura das revoluções científicas. 5. ed. São Paulo: Editora Perspectiva S.A, 1997.

LUCKESI, C. C.; PASSOS, E. S. O conhecimento: significado, processo e apropriação. In: LUCKESI, C. C.; PASSOS, E. S. Introdução à Filosofia: aprendendo a pensar. 4. ed. São Paulo: Cortez, 2002.

MAGNANI, M. C. B.; PINHEIRO, M. M. K. "Regime" e "Informação": a aproximação de dois conceitos e suas aplicações na Ciência da Informação. Liinc em Revista, Rio de Janeiro, v. 7, n.2, p. 593-610, set. 2011. Disponível em:

http://revista.ibict.br/liinc/article/download/3278/2899. Acesso em: 20 maio 2020.

MARTINS, M. T.; SOARES, M. S. B.; FRANCELIN, M. M. Questões preliminares sobre espaços de significação e a organização do conhecimento: conceitos, linguagens e conhecimentos 
marginais. Informe: Estudos em Biblioteconomia e Gestão da Informação, Recife, v. 1, n. 1, p. 78-86, 2012. Disponível em:

https://periodicos.ufpe.br/revistas/INF/article/viewFile/45/83. Acesso em: 20 maio 2020.

SANTAELLA, L. Globalização e multiculturalismo. Anais. AMPAB, 1997. p. 35-47.

UNGER. R. J. G.; FREIRE, I. M. Regimes de informação na sociedade da informação: uma contribuição para a gestão de informação. Revista Digital de Biblioteconomia e Ciência da Informação, Campinas, v. 4, n. 1, p. 87-114, jan./jun. 2008. Disponível em:

https://periodicos.sbu.unicamp.br/ojs/index.php/rdbci/article/view/2014/2135. Acesso em: 20 maio 2020. 